\title{
FARKLI NANOPARTİKÜLLERLE GÜÇLENDİRİLEN MİKRODALGA ENERJİSİ İLE POLİMERİZE OLAN AKRİLİK REZİNİN MEKANİK VE FİZİKSEL ÖZELLİKLERİNİN DEĞERLENDİRİLMESİ
}

\section{EVALUATION OF MECHANICAL AND PHYSICAL PROPERTIES OF MICRO- WAVED ACRYLIC RESIN REINFORCED WITH DIFFERENT NANOPARTICLES}

Uzm. Dt. Muhammet KARCI*

Dr. Öğr. Üyesi Necla DEMİR*

\author{
Arş. Gör. Şakir YAZMAN ${ }^{* * *}$
}

Makale Kodu/Article code: 3819

Makale Gönderilme tarihi; 08.09.2018

Kabul Tarihi: 05.12.2018

DOI: $10.17567 /$ ataunidfd. 492642
Muhammet KarcI: ORCID ID: 0000-0002-7101-822X

Necla Demir: ORCID ID:0000-0003-0927-6962

Şakir Yazman: ORCID ID: 0000-0002-4064-0024

ÖZ

Amaç: PMMA, protetik diş hekimliğinde protez kaide materyali olarak yaygın kullanılmasına rağmen düşük mekanik ve fiziksel özellikler gibi dezavantajlara sahiptir. Bu çalışmanın amacı, mikrodalga enerjisi ile polimerize olan akrilik rezin içerisine ağırlıkça $\% 1,3$ ve 5 oranlarında $\mathrm{Al}_{2} \mathrm{O}_{3}, \mathrm{SiO}_{2}$ ve $\mathrm{TiO}_{2}$ nanopartikülleri ilavesinin yüzey sertliği ve yüzey pürüzlülüğü gibi mekanik ve fiziksel özellikleri üzerine etkisini değerlendirmektir.

Materyal ve Metod: Çalışmamızda üretici firmanın önerileri dikkate alınarak, on farklı grup için toplam yetmiş akrilik rezin örnek $(65 \times 10 \times 3 \mathrm{~mm})$ hazırlanmıştır $(n=7)$. Polisaj ve cilalama işlemleri yapıldıktan sonra yüzey pürüzlülük değerleri $(R a)$ profilometre cihazı ile, yüzey sertliği değerleri ise Rockwell R testi ile ölçülmüştür. Elde edilen verilerin homojenitesi KolmogorovSmirnov testi ile değerlendirildikten sonra iki yönlü varyans analizi ve Tukey HSD testleri kullanılmıştır $(a=0.05)$.

Bulgular: Yüzey pürüzlülüğü değerleri açısından, \%1 oranında nanopartikül ilave edilen grubun pürüzlülük değerleri kontrol grubuna oldukça yakın bulunurken (0.28-0.29), \%3 ve \%5 oranında ilave yapılan grupların pürüzlülük değerleri mikroorganizma tutulumu için kritik değerden $(0.2 \mu \mathrm{m})$ çok yüksek $(0.46-0.84)$ bulunmuştur. Yüzey sertliği değerleri açısından ise nanopartikül ilavesi sonucunda yüzey sertlik değerleri artarken en yüksek değerler \%5 oranında ilave edilen gruplarda bulunmuştur $(p<$ 0.05).

Sonuç: Bu çalışmanın sınırları dahilinde, PMMA'a nanopartikül ilavesi ile mekanik özellikleri geliștirilebilir, ancak nanopartikül ilave yüzdesi arttıkça (\%3 ve \%5) PMMA'nın yüzey pürüzlülük değerlerinin artması ideal doldurucu oranının \%1 olduğunu göstermektedir.

Anahtar kelimeler: Polimetilmetakrilat, Nanopartikül, Yüzey pürüzlülüğü, Yüzey sertliği.

\section{ABSTRACT}

Purpose: PMMA has disadvantages such as low mechanical and physical properties although it is widely used as prosthetic base material in prosthetic dentistry. The aim of this study is to evaluate the effects of adding $\mathrm{Al}_{2} \mathrm{O}_{3}, \mathrm{SiO}_{2}$ and $\mathrm{TiO}_{2}$ nanoparticles in ratios of 1,3 and $5 \mathrm{wt} \%$ to micro-waved acrylic resins on the mechanical and physical properties such as surface hardness and surface roughness.

Material and Method: A total of seventy acrylic resin specimens $(65 \times 10 \times 3 \mathrm{~mm})$ were prepared in different ten groups according to manufacturer's instructions $(n=7)$. After polishing surface roughness values were measured by profilometer, and surface hardness values were measured by Rockwell $\mathrm{R}$ test. Homogeneity of the obtained data was assessed by KolmogorovSmirnov test followed by Two-way ANOVA and Tukey HSD test $(a=0.05)$.

Results: In terms of surface roughness values, the roughness of the groups added with $1 \%$ nanoparticle were very close to control group (0.28-0.29), whereas roughness values of $3 \%$ and $5 \%$ addition groups were found to be very high $(0.46-0.84)$ from the critical value $(0.2 \mu \mathrm{m})$ for microorganism involvement. In terms of surface hardness values, surface hardness values were increased as a result of nanoparticle addition, whereas the highest values were foud in $5 \%$ addition groups $(p<0.05)$.

Conclusion: Within the limitations of this study, the mechanical properties can be improved with the addition of nanoparticles to PMMA, but the increase in the surface roughness values of PMMA with increasing nanoparticle addition ratio (3\% and $5 \%)$ suggests that the ideal filler ratio is $1 \%$.

Keywords: Polymethylmethacrylate, Nanoparticle, Surface roughness, Surface hardness

\footnotetext{
*Alanya Ağız ve Diş Sağlığı Merkezi, Antalya

${ }^{* *}$ Selçuk Üniversitesi Diş Hekimliği Fakültesi Protetik Diş Tedavisi Anabilim Dalı, Konya

*** Selçuk Üniversitesi, Ilgın Meslek Yüksek Okulu, Konya

Kaynakça Bilgisi: Karcı M, Demir N, Yazman Ș.Farklı Nanopartiküllerle Güçlendirilen Mikrodalga Enerjisi ile Polimerize Olan Akrilik Rezinin Mekanik ve

Fiziksel Özelliklerinin Değerlendirilmesi. Atatürk Üniv Diş Hek Fak Derg 2020; 30: 101-106.

Citation Information: Karci M, Demir N, Yazman S.Evaluation of Mechanical and Physical Properties of Micro-Waved Acrylic Resin Reinforced With Different Nanoparticles. J Dent Fac Atatürk Uni 2020; 30: 101-106.
} 


\section{GİRIŞ}

PMMA; düşük maliyeti, biyouyumluluğu, uygulama kolaylığı, ağız ortamında stabil olması ve kabul edilebilir estetik özelliklerinden dolayı sıklıkla protez kaidesi yapımında kullanılmaktadır. Ancak malzemenin düşük mekanik ve fiziksel özelliklere sahip olmasından dolayı kırık oluşması veya deforme olması en büyük dezavantajıdır. ${ }^{1}$

Diş hekimliğinde kullanılan protez kaide rezinleri, ISı, kimyasal, enjeksiyon, görünür ışın ve mikrodalga enerjisi ile polimerize edilebilmektedir. ${ }^{2}$ PMMAnın mikrodalga enerjisi ile polimerizasyonu; popülerliği gittikçe artan, ISı ile polimerizasyon tekniğine kıyasla çok kısa sürede polimerizasyon işleminin gerçekleştiği, rezinin yüzeyindeki ve derinlerindeki kısımlarının homojen bir biçimde ısıtıldığı ve sıcaklığın hızlı bir şekilde artış gösterdiği bir yöntemdir. $^{3}$

Dental materyaller parlak ve pürüzsüz bir yüzeye sahip olmalıdır ve ağız ortamında uzun süre pürüzsüzlüğünü koruyabilmelidir. Pürüzsüz yüzeyler estetik görünümü sağlamanın yanında lekelenmeye neden olan film tabakanın yerleşmesini ve plak retansiyonunun oluşmasını da engellerler. ${ }^{4}$ Plak retansiyonu olabilmesi için yüzeyin pürüzlülüğünün $0.2 \mu$ m'den daha büyük olmalıdır. ${ }^{5}$ Materyallerin yüzey pürüzlülüğü ölçümünde taramalı elektron mikroskobu (SEM), mekanik yüzey profili analizi (profilometre), atomik kuvvet mikroskobu (AFM), üç boyutlu yüzey pürüzlülüğünü ölçen profilometre gibi farklı teknikler kullanılmaktadır. ${ }^{4}$

Yüzey sertliğinde ise materyalin yüzeyinde delici bir uçla ve belirlenmiş bir kuvvetle bir çentik oluşturulur ve çentiğin boyutlarının ölçülmesiyle sertlik değeri hesaplanır. ${ }^{6}$ En sık kullanılan yüzey sertliği ölçme yöntemleri; Barcol, Brinell, Rockwell, Shore A, Vickers ve Knoop'dur. ${ }^{7} \mathrm{Bu}$ testlerin birbirinden farkı, çentik oluşturan ucun farklı şekillerde olması ve sertliğin hesaplama yöntemleridir. ${ }^{1}$ Rockwell metodu; uygulama kolaylığı, diğer metodlara nazaran daha seri sonuçlar alınabilme özelliği ve bu metodla test yapan sertlik ölçme cihazlarının optik ölçüm gerektiren metodlarına (Brinell, Vickers) nazaran daha ucuz olması nedeniyle pratikte en çok kullanılan sertlik ölçme metodlarından biridir. Daha çok yumuşak sertlikteki metaller ve plastiklerin sertliklerinin ölçümünde kullanılmaktadır. ${ }^{8,9}$

Son yıllarda teknolojideki gelişmelere paralel olarak akrilik rezinlerin mekanik özelliklerini, çarpma ve yorulmaya karşı direncini arttırmaya yönelik çeşitli yöntemler geliştirilmiştir. PMMA'ya alternatif yeni bir malzeme geliştirmek ve PMMA'nın kimyasal yapısını modifiye etmenin yanısıra metal, metal oksit tanecikleri, karbon, aramid, cam ve polietilen gibi fiberler çeşitli güçlendirici materyaller kullanılmıştır. ${ }^{10}$ Özellikle son yıllarda nanoteknoloji alanındaki gelişmelerle beraber PMMA'nın içerisine nanopartikül boyutunda metal, metal oksit gibi çeşitli materyallerin ilavesiyle mekanik, fiziksel, kimyasal ve biyolojik özelliklerinin geliştirilmesi amaçlanmaktadır. ${ }^{11}$

Nanopartiküllerin birçok tipi olmasına rağmen literatürde daha çok alüminyum oksit $\left(\mathrm{Al}_{2} \mathrm{O}_{3}\right)$, zirkonyum oksit $\left(\mathrm{ZrO}_{2}\right)$, titanyum oksit $\left(\mathrm{TiO}_{2}\right)$ ve demir oksit $\left(\mathrm{Fe}_{2} \mathrm{O}_{3}\right)$ gibi metal oksit nanopartiküller, silikon dioksit $\left(\mathrm{SiO}_{2}\right)$ ve hidroksi apatit $(\mathrm{HA})$ gibi mineraller ve gümüş $(\mathrm{Ag})$, platin (Pt) ve palladyum (Pd) gibi soymetaller kullanılmıştır. ${ }^{12,13}$ Ancak klinisyenlerin üzerine odaklandığı efektif bir yöntem üzerinde karar kılınamamıştır.

$\mathrm{Bu}$ in vitro çalışmanın amacı, mikrodalga enerjisi ile polimerize olan akrilik rezin tipi içerisine ağırlıkça \%1, 3 ve 5 oranlarında $\mathrm{Al}_{2} \mathrm{O}_{3}, \mathrm{SiO}_{2}$ ve $\mathrm{TiO}_{2}$ nanopartikülleri ilavesinin yüzey sertliği (Rockwell $\mathrm{R}$ ) gibi mekanik özellik ve yüzey pürüzlülüğü gibi fiziksel özellik üzerine etkilerini araştırmaktır. Çalışmanın sıfır hipotezi, farklı oranlarda nanopartikül ilavesi sonucu mikrodalga enerjisi ile polimerize olan akrilik rezin örneklerin yüzey sertlik ve yüzey pürüzlülüğü değerlerinin değişmemesidir.

\section{MATERYAL VE METOD}

Yapılan güç analizi sonrasında güç değeri 0.85 alınarak yapılan örneklem genişliği analizinde her bir grupta alınması gereken örneklem sayısı 7 adet olarak bulunmuştur. Standart boyutlardaki örneklerin hazırlanması için ISO 1567 standardına uygun olarak $65 \times 10 \times 3 \mathrm{~mm}$ boyutlarında dikdörtgenler prizması şeklinde şekillendirilmiş mum kalıplar (Cavex Set Up Regular, Cavex Holland BV, Haarlem, Hollanda) kullanılmıştır. Nanopartikül ilavesi yapılmayan kontrol grubu için gerekli olan toz ve likit $1 / 10000$ gr hassasiyetteki terazi ile hesaplanmıştır. Nanopartikül ilavesi yapılacak gruplar için ise, akrilik tozunun ağırlıkça \%1, \%3 ve $\% 5$ oranında $\mathrm{Al}_{2} \mathrm{O}_{3}$ nanopartikülü (\% 99.5 saflık oranı, $18 \mathrm{~nm}$ partikül boyutu, $140 \mathrm{~m}^{2} / \mathrm{g}$ spesifik yüzey alanı ve $3.9 \mathrm{~g} / \mathrm{cm}^{3}$ yoğunluğa sahip beyaz renkli, Nanografi, Ankara, Türkiye), $\mathrm{SiO}_{2}$ nanopartikülü (\% 99.5 saflık oranı, $15 \mathrm{~nm}$ partikül boyutu, $150-550 \mathrm{~m}^{2} / \mathrm{g}$ spesifik yüzey alanı ve $2.2 \mathrm{~g} / \mathrm{cm}^{3}$ yoğunluğa sahip beyaz renkli, Nanografi, Ankara, Türkiye) ve $\mathrm{TiO}_{2}$ nanopartikülü (\% 99.5 saflık oranı, $13 \mathrm{~nm}$ partikül boyutu, $60 \mathrm{~m}^{2} / \mathrm{g}$ 
spesifik yüzey alanı ve $4.1 \mathrm{~g} / \mathrm{cm}^{3}$ yoğunluğa sahip beyaz renkli, Nanografi, Ankara, Türkiye) yine aynı terazi ile hesaplanmıştır.

Ağırlıkça farklı oranlarda nanopartiküllerin akrilik içerisinde homojen dağıtma işlemi bilyeli değirmende (Fritsch Pulverisette-5, Idar-Oberstein, Almanya) oda sıcaklığında kuru olarak 400 dev/dak. dönme hızında iki saat karıştırılarak yapılmıştır. Karıştırma işleminde $7 \mathrm{~mm}$ çapında çelik bilyeler kullanılmıştır (Şekil $1)$.

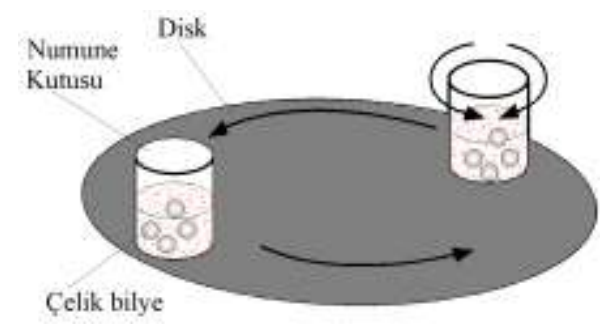

Şekil 1. Karıştırma işleminin şematik gösterimi

Mum örnekler mikrodalga enerjisiyle polimerizasyona uygun yapıda fiberle güçlendirilmiş özel plastik muflalara (FRP Flask, GC Industrial Corp: Tokyo, Japonya) yerleştirilmiştir. Mufla, $2450 \mathrm{MHz}$ mikrodalga salınımlı ve $500 \mathrm{~W}$ güce sahip, mutfak tipi mikrodalga fırının (Arçelik Intellowave MD554, Boiu, Türkiye) içine yerleştirilip 500 W'ta 1 dakika boyunca mikrodalga ısısına maruz bırakılmıştır. Mikrodalga polimerizasyonu için üretilmiş olan Acron MC (Microwave Curing Denture Base Resin, GC Dental, Tokyo, Japonya) üretici firma önerileri doğrultusunda toz/likit oranı $100 \mathrm{gr} / 43 \mathrm{ml}$ olacak şekilde karıştırılarak üretici firma önerileri doğrultusunda 3 dakika 500 W'ta mikrodalga ışımasına tabi tutulmuşlardır. Muflalar 30 dakika oda ısısında soğumaya bırakıldıktan sonra tam soğutma için akan soğuk su altında da yaklaşık 20 dakika bekletilmişlerdir. Elde edilen örneklerin bitirme işlemleri aynı klinisyen tarafından 200, 400 ve 600 grenli zımpara kağıtları (Waterproof silikon carbide paper, English Abrasives Ltd., Londra, İngiltere) kullanılarak ortalama 5 dakika boyunca su soğutması ile gerçekleştirilmiştir. Elde edilen gruplardan birer örnek Şekil 2'de gösterilmiştir.

Yüzey pürüzlülüğü ölçümleri Konya KOSGEP Laboratuarı'na ait olan Mitutoyo Surftest SJ 201P (Mitutoyo Corporation, Tokyo, Japonya) profilometre cihazı ile yapılmıştır (Şekil 3). Çalışmamızda ölçüm uzunluğu $5.5 \mathrm{~mm}, \mathrm{n}=5$, cut off değeri ise $0.25 \mathrm{~mm}$ olarak olarak ayarlanmıştır. Her örneğin ortalama yü- zey pürüzlülüğü değeri $(R a), 3$ farklı bölgeden kayıt alınarak hesaplanmıştır.

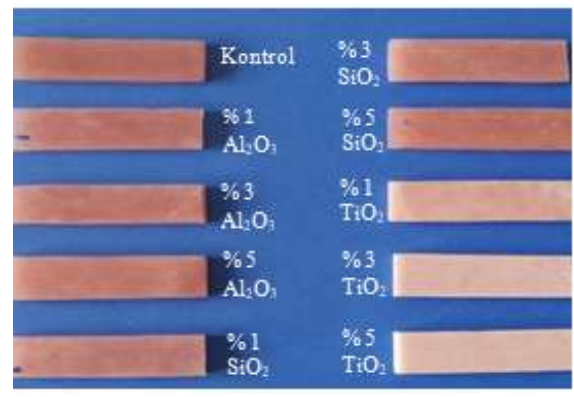

Şekil 2. Çalışmada kullanılan örnekler

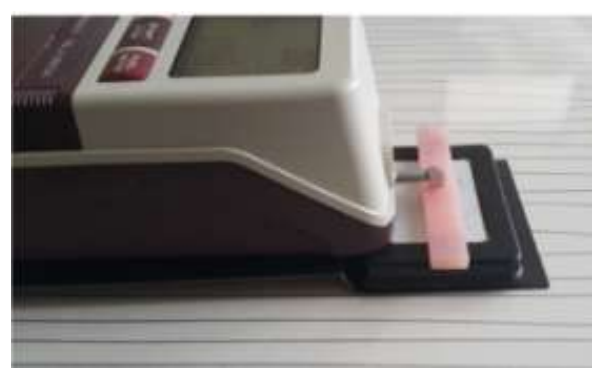

Şekil 3. Yüzey pürüzlülüğü ölçümünün yapılışı

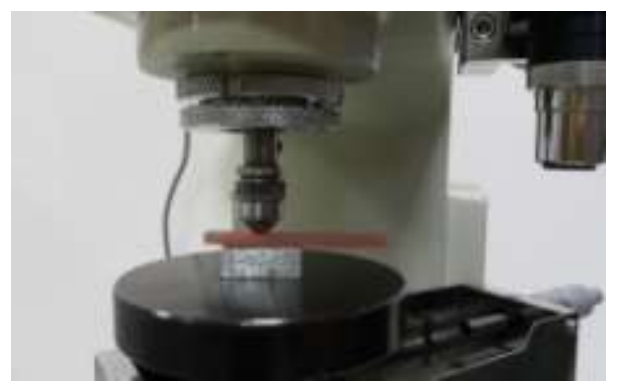

Şekil 4. Yüzey sertlik testinin yapılışı

Sertlik deneyleri Selçuk Üniversitesi Mühendislik Fakültesi Metalurji ve Malzeme Mühendisliği Anabilim Dalı Laboratuvarı'nda DİGİROCK-RBOV (Bulut Makina, İstanbul, Türkiye) sertlik ölçüm cihazı ile yapılmıştır (Şekil 4). Rockwell-R sertlik ölçüm yöntemi ( $d=1 / 2 "$ bilya çapı; uygulanan yük=60 kg) ile yapılan bu testte, her örnekten 3'er ölçüm yapılarak ortalama değer hesaplanmıştır.

Çalışmada elde edilen bulgular değerlendirilirken, istatistiksel analizler için IBM SPSS 22.0 istatistik paket programı kullanılmıştır. Çalışma verilerinin homojenitesi Kolmogorov-Smirnov testi ile değerlendirilmiştir. Gruplar arası ortalamaların karşılaştırılmasında iki yönlü varyans analizi (ANOVA) testi 
kullanılmış, anlamlı bulunan ortalama farklılıklarının tespitinde çoklu karşılaştırma Tukey HSD testinden yararlanılmıştır $(p=0.05)$.

\section{BULGULAR}

Çalışma gruplarına ait yüzey sertliği ve yüzey pürüzlülüğü değerleri Tablo 1 ve Tablo 2'de gösterilmiştir. En yüksek pürüzlülük değerleri $\% 5$ oranında $\mathrm{Al}_{2} \mathrm{O}_{3}, \mathrm{SiO}_{2}$ ve $\mathrm{TiO}_{2}$ nanopartikülü ilave edilen gruplarda ölçülürken; en düşük pürüzlülük değerleri kontrol grubunda ölçülmüştür $(p<0.05)$. Yüzey pürüzlülük değerleri nanopartikül tipinden etkilenmemiş ve nanopartikül yüzdesi ile doğru orantılı bir artış görülmüştür.

Yüzey sertlik değerlerine ilişkin en yüksek değerler $\% 3$ ve $\% 5$ oranlarında nanopartikül ilavesi yapılan gruplarda görülürken, en düşük değerler kontrol grubunda görülmüştür $(p<0.05)$. \%3 ve \%5 grupları ara- sında anlamlı bir farklılık bulunamamıştır $(p>$ 0.05). Yüzey sertlik değerleri nanopartikül tipinden etkilen- memiştir.

Tablo 1. Akrilik rezin örnekler için yüzey pürüzlülüğü değerleri $(\mu \mathrm{m})$

\begin{tabular}{|c|c|r|r|r|}
\hline Gruplar & Minimum & Maksimum & Ortalama & $\begin{array}{c}\text { Standart } \\
\text { Sapma }\end{array}$ \\
\hline Kontrol & 0,1 & 0,22 & $0,16^{\mathrm{d}}$ & 0,06 \\
\hline$\% 1 \mathrm{Al}_{2} \mathrm{O}_{3}$ & 0,2 & 0,38 & $0,29^{\mathrm{c}}$ & 0,09 \\
\hline$\% 3 \mathrm{Al}_{2} \mathrm{O}_{3}$ & 0,42 & 0,56 & $0,49^{\mathrm{b}}$ & 0,05 \\
\hline$\% 5 \mathrm{Al}_{2} \mathrm{O}_{3}$ & 0,7 & 0,84 & $0,78^{\mathrm{a}}$ & 0,07 \\
\hline$\% 1 \mathrm{SiO}_{2}$ & 0,21 & 0,35 & $0,28^{\mathrm{c}}$ & 0,08 \\
\hline$\% 3 \mathrm{SiO}_{2}$ & 0,5 & 0,63 & $0,58^{\mathrm{b}}$ & 0,06 \\
\hline$\% 5 \mathrm{SiO}_{2}$ & 0,7 & 0,84 & $0,75^{\mathrm{a}}$ & 0,07 \\
\hline$\% 1 \mathrm{TiO}_{2}$ & 0,19 & 0,37 & $0,28^{\mathrm{c}}$ & 0,05 \\
\hline$\% 3 \mathrm{TiO}_{2}$ & 0,39 & 0,55 & $0,46^{\mathrm{b}}$ & 0,09 \\
\hline$\% 5 \mathrm{TiO}_{2}$ & 0,7 & 0,82 & $0,74^{\mathrm{a}}$ & 0,09 \\
\hline
\end{tabular}

Tablo 2. Akrilik rezin örnekler için yüzey sertliği değerleri (Rockwell R)

\begin{tabular}{|c|c|c|c|c|}
\hline Gruplar & Minimum & Maksimum & Ortalama & $\begin{array}{c}\text { Standart } \\
\text { Sapma }\end{array}$ \\
\hline Kontrol & 118,8 & 120,1 & $119,48^{\mathrm{c}}$ & 0,56 \\
\hline$\% 1 \mathrm{Al}_{2} \mathrm{O}_{3}$ & 119,7 & 122,7 & $120,76^{\mathrm{b}}$ & 0,75 \\
\hline$\% 3 \mathrm{Al}_{2} \mathrm{O}_{3}$ & 120,2 & 122,9 & $121,37^{\mathrm{a}}$ & 0,72 \\
\hline$\% 5 \mathrm{Al}_{2} \mathrm{O}_{3}$ & 120,5 & 123,6 & $121,84^{\mathrm{a}}$ & 1,3 \\
\hline$\% 1 \mathrm{SiO}_{2}$ & 118,9 & 122,5 & $120,51^{\mathrm{b}}$ & 0,88 \\
\hline$\% 3 \mathrm{SiO}_{2}$ & 119,9 & 122,3 & $121,23^{\mathrm{a}}$ & 1 \\
\hline$\% 5 \mathrm{SiO}_{2}$ & 120,7 & 123,4 & $121,87^{\mathrm{a}}$ & 0,64 \\
\hline$\% 1 \mathrm{TiO}_{2}$ & 118,2 & 122,3 & $120,37^{\mathrm{b}}$ & 1,62 \\
\hline$\% 3 \mathrm{TiO}_{2}$ & 119,8 & 122,8 & $121,07^{\mathrm{a}}$ & 0,89 \\
\hline$\% 5 \mathrm{TiO}_{2}$ & 120 & 122,4 & $121,38^{\mathrm{a}}$ & 0,92 \\
\hline
\end{tabular}

\section{TARTIŞMA}

Elde edilen analiz sonuçlarına göre; nanopartikül ilavesi sonucunda yüzey sertliği ve yüzey pürüzlülüğü değerlerinde artış görülmüştür. Bu doğrultuda çalışmanın hipotezi red edilmiştir.

Nanoteknoloji alanındaki gelişmelerle birlikte çok daha küçük boyutlarda doldurucular (<100 nm) kullanılmaya başlanmıştır. ${ }^{14}$ Materyalin yüzeyinin nanometre boyutunda olması ona kendine has özellikler kazandırmaktadır. Hacmine göre çok geniş yüzey alanına sahip olmaları malzemede yeni mekanik, kimyasal, elektriksel, optik, magnetik, elektro-optik ve magneto-optik özellikler oluşmaktadır. ${ }^{15,16}$

Polimer kompozitlerin mekanik özelliklerinin geliştirilmesinde doldurucu partikülün şekli, büyüklüğü, polimer matriks içindeki dağı̆ımı ve matrikse bağlantısı çok önemli paya sahiptir. Metal oksitlerin boyutları uygun karıştırma için küçük olmalıdır. ${ }^{17} \mathrm{Bu}$ çalışmada da ortalama $121.2 \mu \mathrm{m}^{\prime}$ lik akrilik tozlarının içerisine 15 nm'lik metal oksit $\left(\mathrm{Al}_{2} \mathrm{O}_{3}\right.$ ve $\left.\mathrm{TiO}_{2}\right)$ ve mineral $\left(\mathrm{SiO}_{2}\right)$ partikülleri karıştırılmıştır. Böylece partiküller polimer partikülleri arasındaki çatlakları doldurarak heterojen bir karışım oluşmasını ve polimer zincir parçalarının hareket etmesini önlemektedir. Ayrıca partiküllerin rezin içerisinde gömülmesini sağlayacak şekilde doldurucu yüzdesi de düşük olmalıdır. Düşük dansiteye sahip olmaları da akrilik rezin hafif ağırlıklarının korunmasına sebep olmaktadır. ${ }^{18}$

Dental materyallerin yüzey pürüzlülüğü, literatürde sıklıkla araştırılmış ve materyallerin serbest yüzey enerjisini etkilediği gösterilmiştir. ${ }^{19} \mathrm{Bu}$ da; pürüzlü yüzeylerin yüksek serbest yüzey enerjisi ve mikrobiyal plak oluşumuna yol açtığı anlamına gelmektedir. ${ }^{20}$ Yüzey pürüzlülüğü özellikle protezle ilişkili stomatitisin patogenezinde önem taşıyan Candida albicans'ın yapışması ve tutunmasını uyarır, bu da materyale komşu ağız dokularında çürük, gingival ve periodontal hastalıklar ve protezle artmış stomatitisin görülme sıklığında artışa neden olabilir. ${ }^{21}$

Literatürde mikrodalga enerjisi ile polimerize olan akrilik rezinlerle ilgili çok fazla çalışma olmamakla beraber çalışmaların çoğu ısı ile polimerize olan akrilik rezinlerle ilgilidir.

Akkuş ve ark. ${ }^{22}$ ve Ismail ve Jasim² ${ }^{23}$, ISı ile polimerize olan akrilik rezin içerisine karıştırarak yüzey pürüzlülüğünü incelemişlerdir ve nanopartikül ilavesi sonucu anlamlı bir farklılık görmemişlerdir. Buna karşın Vojdani ve ark. ${ }^{24}$ ve Safi ${ }^{25}$ da yüzey pürüzlülüğünde artış gözlemlemişlerdir. Bizim çalışmamızda da bu çalış- 
malara benzer şekilde, yüzey pürüzlülüğü değerleri nanopartikül ilavesi ile artmış ve en yüksek değerler \%5 oranında nanopartikül ilave edilen gruplarda görülmüştür.

Yüzey sertliğinin artması rezin materyalin daha yüksek aşınma direncine sahip olmasını sağlamaktadır. Özellikle oklüzal splint uygulamaları gibi dental uygulamalarda önemli olmaktadır. Nanopartikül ilavesi ile sertliğin artması, yüksek dayanıklıı̆a sahip akrilik rezinler yerine geleneksel akrilik rezinlerin kullanılmasına yol açmakta bu durumda \%60-70'e varan daha düşük maliyet anlamına gelebilir. ${ }^{22}$

Akkuş ve ark. ${ }^{22}$ ve Mc Nally ve ark. ${ }^{26}$, nanopartikül ilavesi ile akrilik rezinin yüzey sertliğinde istatistiksel olarak bir farklılık görmezken; bazı araştırmacllar, \%1'den daha yüksek oranlarda nanopartikül ilavesi sonrasında yüzey sertliğinde istatistiksel olarak anlamlı bir artış görmüşlerdir. ${ }^{23,24,27,28}$

Literatürde mikrodalga enerjisi ile polimerize olan akrilikle yapılan tek çalışmada ise Silva ve ark. ${ }^{29}$, mikrodalga enerjisi ile polimerize olan akrilik rezine silikon dioksit $\left(\mathrm{SiO}_{2}\right)$ nanopartikülünü $\% 0.1,0.5,1$ ve 5 oranlarında ilave ederek yüzey sertliğini değerlendirdikleri çalışmada sertlik değerleri azalmıştır.

Bu çalışmada da yüzey sertliği değerleri nanopartikül ilavesi ile artmış ve en yüksek değerler \%5 oranında nanopartikül ilave edilen gruplarda görülmüştür.

Ağız içinde kullanılan malzemelerin renklerinin estetik olarak kabul edilebilir düzeyde olması gerekmektedir. Nanopartikül ilave edilen akrilik rezinlerin de renk olarak kabul edilebilir düzeyde olması gerekmektedir. ${ }^{30}$ Shirkavand ve Moslehifard ${ }^{31}$ ve Ghahremani ve ark. ${ }^{32}, \mathrm{TiO}_{2}$ nanopartikülü ilavesinden sonra akrilik rezini renk pigmentleri ile modifiye etmişlerdir.

$\mathrm{Bu}$ çalışmada da özellikle \%5 oranında $\mathrm{TiO}_{2}$ nanopartikülü ilave edilen örneklerin renklerinde opaklaşma tespit edilmiştir. Bunun önüne geçmek için yeni yapılacak çalışmalarda renk pigmentlerinin kullanımı söz konusu olabilir.

\section{SONUÇ}

Yapılan çalışmanın sonuçlarına göre; nanopartikül ilavesi sonucu bir yandan akrilik rezinlerin mekanik özelliklerinden yüzey sertliği gelişirken, bir yandan da partikül ilavesinin olumsuz sonuçlarından sayılabilecek yüzey pürüzlülüğünde artış görülmüştür. Bu yüzden hem yüzey sertliğini arttıran hem de yüzey pürüzlülüğünü eşik değerin çok fazla üzerine çıkar- mayan oranlarda nanopartikül ilavesi önerilmektedir. Kliniği daha iyi taklit etmesi açısından in vivo çalışmaların sonuçlarının da değerlendirilmesi gerekmektedir.

NOT: Calışmada herhangi bir yazar, kurum ya da kuruluş ile çıkar çatışması içerisinde bulunmamaktadır. Makale daha önce hiçbir yerde yayınlanmamış ve yayınlanmak üzere işlem görmemektedir

\section{KAYNAKLAR}

1. Alla R, Raghavendra K, Vyas R, Konakanchi A. Conventional and contemporary polymers for the fabrication of denture prosthesis: part I-overview, composition and properties. Int J Appl Dent Sci 2015; 1:82-9.

2. Anusavice KJ. Dental Polymers. In: Phillips' Science of Dental Materials. 11th ed. St. Louis; Missouri: 2003. p. 75-98.

3. Memon MS, Yunus N, Razak AA. Some mechanical properties of a highly cross-linked, microwavepolymerized, injection-molded denture base polymer. Int J Prosthodont 2001; 14:214-8.

4. Kakaboura A, Fragouli M, Rahiotis C, Silikas N. Evaluation of surface characteristics of dental composites using profilometry, scanning electron, atomic force microscopy and gloss-meter. J Mater Sci Mater Med 2007; 18:155-63.

5. Joniot S, Salomon JP, Dejou J, Gregoire G. Use of two surface analyzers to evaluate the surface roughness of four esthetic restorative materials after polishing. Oper Dent 2006; 31:39-46.

6. O'Brien WJ. Dental Materials and Their Selection. 3th ed. St. Louis; Missouri: 2002. p. 145-67.

7. Sakaguchi RL, Powers JM. Craig's restorative dental materials. 13th ed. St. Louis; CV Mosby: Elsevier 2012. p. 112-34.

8. O'Brien WJ. Dental Materials and Their Selection. 2nd ed. St. Louis; Missouri: 1997. p. 79-95, 25972.

9. Craig RG, Powers JM, Wataha JC. Dental Polymers. In: Dental Materials, Properties and Manipulatio. 12th ed. St. Louis; CV Mosby: 2000. p. 145-76.

10. Vallittu PK. A review of methods used to reinforce polymethyl methacrylate resin. J Prosthodont 1995; 4:183-7.

11. Tacir I, Kama J, Zortuk M, Eskimez S. Flexural properties of glass fibre reinforced acrylic resin polymers. Aust Dent J 2006; 51:52-6. 
12. Salman TA, Khalaf HA. The influence of adding of modified $\mathrm{ZrO}_{2}-\mathrm{TiO}_{2}$ nanoparticles on certain physical and mechanical properties of heat polymerized acrylic resin. J Bagh Coll Dent 2015; 3:33-9.

13. Alhareb $A$, Akil $\mathrm{H}$, Ahmad Z. Influence of $\mathrm{Al}_{2} \mathrm{O}_{3} / \mathrm{Y}$ TSZ mixture as filler loading on the radiopacity of PMMA denture base composites. Procedia Chem 2016; 19:646-50.

14. Allaker R. The use of nanoparticles to control oral biofilm formation. J Dent Res 2010; 89:1175-86.

15. Hajipour MJ, Fromm KM, Ashkarran AA, Jimenez de Aberasturi $D$, de Larramendi IR, Rojo $T$, et al. Antibacterial properties of nanoparticles. Trends Biotechnol 2012; 30:499-511.

16. Lainović T, Blažić L, Potran M. Nanotechnology in dentistry: current state and future perspectives. Stomatol Glas Srb 2012; 59:44-50.

17. Unal $H$, Mimaroglu $A$. Influence of filler addition on the mechanical properties of nylon- 6 polymer. J Reinfor Plast Comp 2004; 23:461-9.

18. Korkmaz T, Dogan A, Usanmaz A. Dynamic mechanical analysis of provisional resin materials reinforced by metal oxides. Biomed Mater Eng 2004; 15:179-88.

19. Bayraktar Y, Doğan D, Ercan E. Farklı polisaj sistem ve tekniklerinin üç farklı kompozit rezinin yüzey pürüzlülüğüne etkisi. Atatürk Üniversitesi Dişhekimliği Fak. Dergisi 2013; 21:192-8.

20. Hoeksema AR, Vissink A, Peters LL, Meijer HJ, Raghoebar GM, Visser A. Peri-implant health in people aged 75 and over with an implant-retained overdenture in the mandibula. Ned Tijdschr Tandheelkd 2015; 7:383-90.

21. Zissis AJ, Polyzois GL, Yannikakis SA, Harrison A. Roughness of denture materials: a comparative study. Int J Prosthodont 2000; 13:136-40.

22. Akkuş B, Yazman S, Ozturk AN, Akdemir A. Mechanical and thermal properties of $\mathrm{Al} 2 \mathrm{O} 3$ and $\mathrm{SiO} 2$ nanoparticles addition heat cured acrylic resin. J Enhan Res Sci Tech Eng 2015; 4:219-26.

23. Ismail IJ, Jasim BS. The effect of silanized alumina nano-fillers addition on some physical and mechanical properties of heat cured polymethyl methacrylate denture base material. J Bagh Coll Dent 2014; 26:18-23.

24. Vojdani M, Bagheri $R$, Khaledi AAR. Effects of aluminum oxide addition on the flexural strength, surface hardness, and roughness of heat- polymerized acrylic resin. J Dent Sci 2012; 7:23844.

25. Safi IN. Evaluation the effect of nano-fillers $\left(\mathrm{TiO}_{2}\right.$, $\mathrm{AL}_{2} \mathrm{O}_{3}, \mathrm{SiO}_{2}$ ) addition on glass transition temperature, E-Moudulus and coefficient of thermal expansion of acrylic denture base material. J Bagh Coll Dent 2014; 2:37-41.

26. Mc Nally L, O'sullivan D, Jagger D. An in vitro investigation of the effect of the addition of untreated and surface treated silica on the transverse and impact strength of poly (methyl methacrylate) acrylic resin. Biomed Mater Eng 2006; 16:93-100.

27. Ahmed MA, El-Shennawy M, Althomali YM, Omar AA. Effect of titanium dioxide nano particles incorporation on mechanical and physical properties on two different types of acrylic resin denture base. J Nano Sci Eng 2016; 6:103-11.

28. Alnamel HA, Mudhaffer $M$. The effect of silicon di oxide nano-fillers reinforcement on some properties of heat cure polymethyl methacrylate denture base material. J Bagh Coll Dent 2014; 26:32-6.

29. da Silva LH, Feitosa SA, Valera MC, de Araujo MA, Tango RN. Effect of the addition of silanated silica on the mechanical properties of microwave heat-cured acrylic resin. Gerodontology 2012; 29:e1019-23.

30. Ghaffari T, Hamedirad F, Ezzati B. In vitro comparison of compressive and tensile strengths of acrylic resins reinforced by silver nanoparticles at $2 \%$ and $0.2 \%$ concentrations. J Dent Res Dent Clin Dent Prospects 2014; 8:204-9.

31. Shirkavand S, Moslehifard E. Effect of TiO2 nanoparticles on tensile strength of dental acrylic resins. J Dent Res Dent Clin Dent Prospects 2014; 8:197-203.

32. Ghahremani L, Shirkavand S, Akbari F, Sabzikari N. Tensile strength and impact strength of color modified acrylic resin reinforced with titanium dioxide nanoparticles. J Clin Exp Dent 2017; 9:e661-e5.

\author{
Yazışma Adresi \\ Muhammet Karcı \\ Alanya Ağız ve Diş Sağlığı Merkezi, Antalya \\ Phone: +90-242-519 1944 \\ Fax: +90-242-519 1928 \\ e-mail: muhammetdt48@hotmail.com
}

